\title{
Effects of oestrogen on the extracellular matrix in the endometrium of postmenopausal women
}

\author{
M Iwahashi, A Ooshima, R Nakano
}

\begin{abstract}
Aim-To obtain insight into the effects of oestrogen on extracellular matrix (ECM) in the postmenopausal endometrium.

Methods-The distribution of the components of the ECM, including collagen types I, III, IV, and VI, and laminin, was investigated in the human postmenopausal endometrium by an indirect immunofluorescence method with specific monoclonal antibodies and a polyclonal antibody. Collagens were also extracted from the endometrial tissues of postmenopausal women who had or had not been treated with oestrogen for three weeks.
\end{abstract}

Results-Immunohistochemical studies demonstrated that type I collagen was the predominant interstitial collagen, and that types III and VI collagens were absent or very sparsely distributed in the stroma of the postmenopausal endometrium. However, types I, III, and VI collagens were diffusely localised in the stroma of the postmenopausal endometrium after administration of oestrogen. Even though type IV collagen was not seen in the basement membrane of the endometrial glands in the endometrium of postmenopausal women in the absence of oestrogen treatment, both type IV collagen and laminin were localised exclusively in the basement membrane of the endometrial glands in the postmenopausal endometrium after three weeks of oestrogen treatment. The level of type III collagen relative to that of type $I$ collagen was significantly increased $(p<0.01)$ in the endometrium of oestrogen treated postmenopausal women compared with nontreated postmenopausal women.

Conclusions-Conjugated equine oestrogen might induce changes in the distribution of components and in the composition of the ECM in the endometrium of postmenopausal women.

(f Clin Pathol 1997;50:755-759)

Keywords: extracellular matrix; postmenopausal endometrium; oestrogen

After menopause, atrophy is apparent and mitotic activity ceases in the endometrium. Epithelial cells shrink in size and the stroma becomes fibrotic. Compact eosinophilic material accumulates in endometrial glands, occasionally engorging them. This process causes a histological picture known as "cystic atrophy", which is characteristic of the endometrium of postmenopausal women. These atrophic changes can also occur in women who are treated with agents that suppress hypophysealovarian function, including gonadotrophin releasing hormone agonists and antagonists.

The extracellular matrix (ECM) is considered to play an important role in the stability of tissues, and in the regulation of the growth and differentiation of cells. ${ }^{23}$ Synthesis, accumulation, and catabolism of the ECM are involved in wound healing and in the initiation and progression of numerous diseases. ${ }^{4}$ The ECM of the human endometrium and decidua has been studied in early pregnancy. ${ }^{5}$ However, the changes of the ECM in the endometrial tissues of postmenopausal women are not fully understood. In the present study, we investigated the effects of conjugated equine oestrogen on the components of the ECM in the endometrium of postmenopausal women by immunofluorescence staining and sodium dodecyl sulphatepolyacrylamide gel electrophoresis (SDSPAGE).

\section{Methods}

The project was approved by the Committee on Investigations Involving Human Subjects of Wakayama Medical College. Informed consent was obtained from each subject after the purpose and nature of the study had been fully explained.

\section{PATIENTS}

Patients were postmenopausal women undergoing hysterectomy because of problems such as prolapsed uterus. Ten women (aged 58-78 years) had been treated with conjugated equine oestrogen (Premarin; Wyeth-Ayerst Laboratories, Philadelphia, Pennsylvania, USA) $0.625 \mathrm{mg}$ daily for three weeks, and 10 women (aged 57-81 years) had not received such treatment

\section{TISSUES}

Endometrial tissues were selected from specimens obtained at hysterectomy. Specimens were immediately frozen in liquid nitrogen. We excluded all necrotic tissues from histological analysis.

\section{PRIMARY ANTIBODIES}

Monoclonal antibodies (MoAb) againșt human collagen types I, III, IV, and VI were used. Preparation of the antibodies has been described previously. ${ }^{6}$ The specificity of each antibody was determined by immunoblotting or by inhibition in an ELISA. No cross 


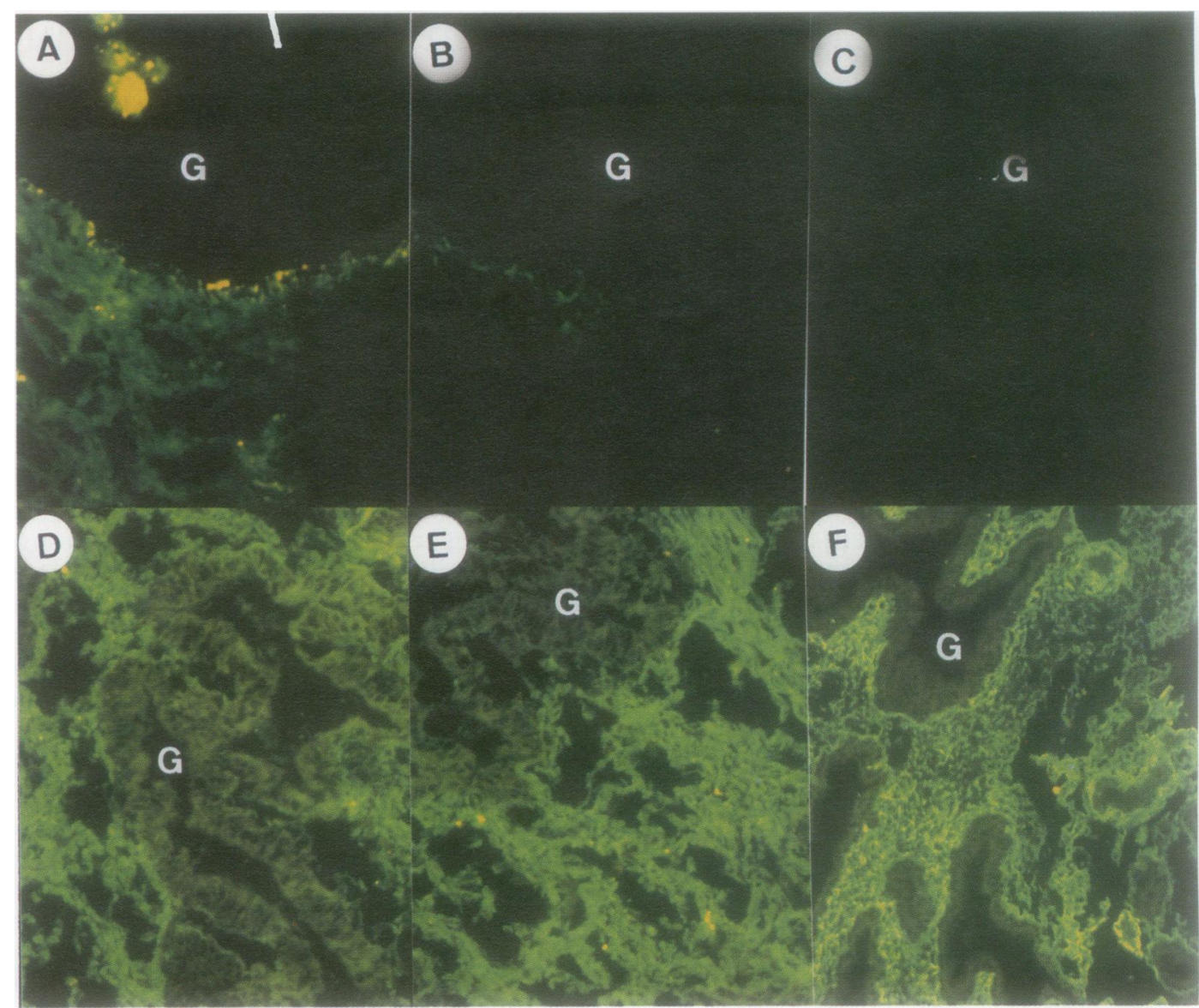

Figure 1 Immunofluorescence micrographs of the endometrium from non-treated $(A-D)$ and oestrogen treated $(E-H)$ postmenopausal women with $M o A b$ specific for interstitial collagens. Type $I(A, D)$, type $I I I(B, E)$, and type VI $(C, F)$. $G$, endometrial gland. (Original magnification, $\times 250$ ).

reactions were recognised among these antibodies. A polyclonal antibody specific for human laminin (Gibco Lab Co, Grand Island, New York, USA) was used that did not cross react with types I, III, IV, or VI collagens or fibronectin.

\section{IMMUNOHISTOCHEMISTRY}

Immunohistochemical analysis was performed by the standard indirect immunofluorescence method. In brief, $3 \mu \mathrm{m}$ frozen sections were rehydrated in phosphate buffered saline (PBS) at room temperature. They were incubated with the primary antibody (diluted $1 / 100$ in PBS) for 12 hours at $4^{\circ} \mathrm{C}$ in a humidified chamber. After incubation, each section was incubated for one hour at room temperature with human plasma preabsorbed, fluorescein isothiocyanate conjugated goat antibodies against mouse or rabbit immunoglobulins that had been diluted 1/100 in PBS (Organon Teknik, Co, West Chester, Pennsylvania, USA).

SDS-PAGE OF PEPSIN SOLUBILISED COLLAGENS Minced samples of human endometrium were washed overnight in cold distilled water and freed from blood. Tissues were homogenised in 50 volumes of $0.5 \mathrm{M}$ acetic acid that contained $1 \mathrm{mg} / \mathrm{ml}$ pepsin (Sigma, St Louis, Missouri, USA). Collagens were extracted by previously described methods. ${ }^{7}$ The solubility of the tissue collagen from each endometrial sample was estimated by comparing the hydroxyproline content of the initial homogenate with that of the final solution of collagen. ${ }^{8}$ Estimation of the relative abundance of the $\alpha 1$ (III) chain was performed by interrupted gel electrophoresis. Electrophoresis was performed in an $8 \%$ polyacrylamide slab gel (Sigma) as previously described. ${ }^{9}$ Aliquots of $25 \mathrm{ml}$ of each solution of heat denatured collagens were applied to the gel and subjected to electrophoresis at $80 \mathrm{~mA}$. After 1.5 hours the current was switched off and sample wells were filled with a solution of $20 \% \beta$ mercaptoethanol (Wako Chemical Co, Osaka, Japan) in gel buffer for one hour to cleave the intramolecular disulphide bonds of type III collagen, $(\alpha 1$ (III)) 3 . Then electrophoresis was resumed and allowed to continue for another hour. Each collagen $\alpha$ chain was stained with Coomassie brilliant blue (Sigma) and measured by densitometry. The relative amounts of $\alpha 1$ (III) chains were calculated by dividing the intensities of bands of $\alpha 1$ (III) by those of $\alpha 1$ (I).

STATISTICAL ANALYSIS

The ratios of intensity of bands of $\alpha 1$ (III) to $\alpha 1$ (I) chains, as estimated by densitometry, were represented as means (SEM), and analysed by analysis of variance (ANOVA) and Student's $t$ test, using a StatView software program on a Macintosh computer. Two tailed $p$ values of less than 0.05 were considered significant. 


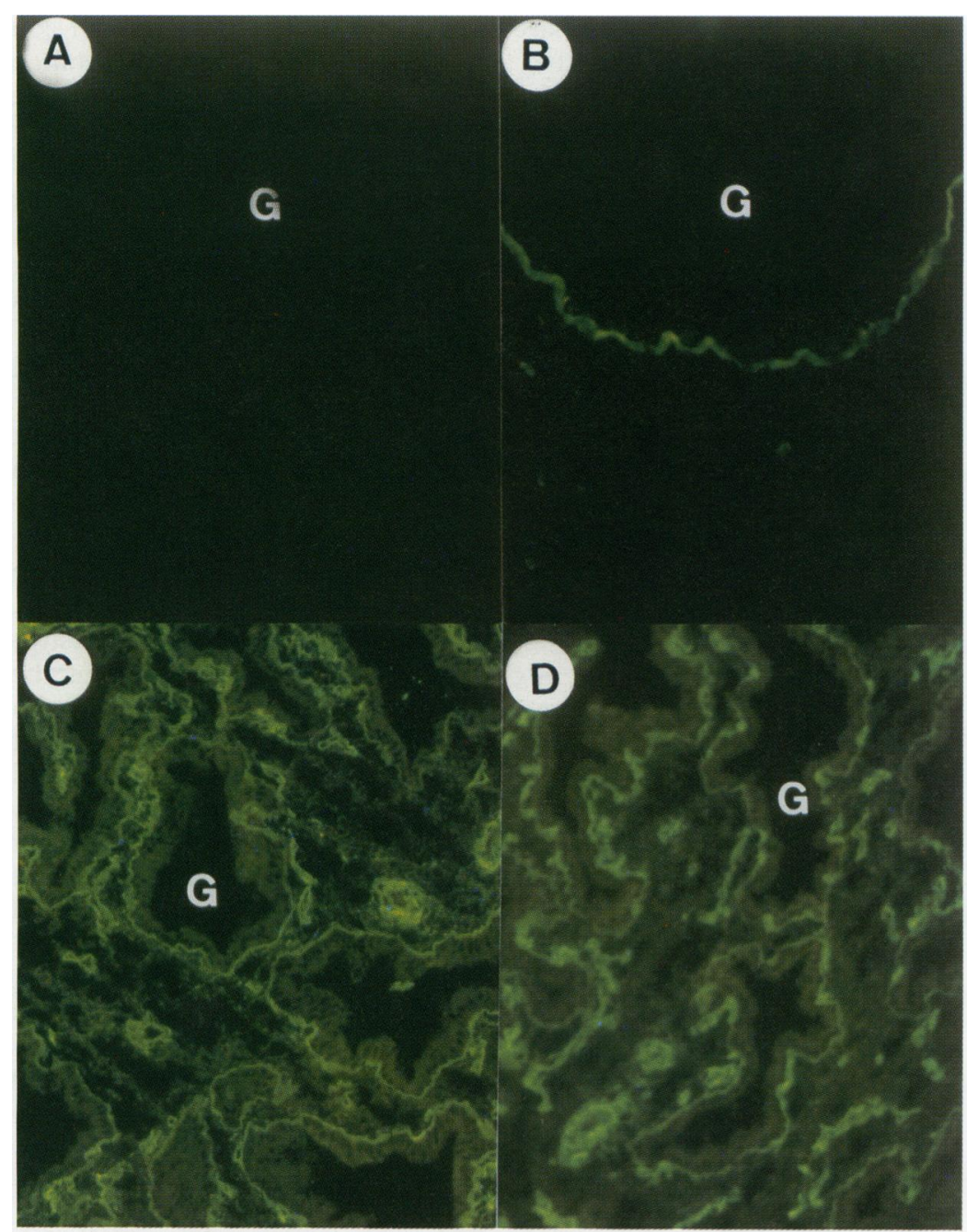

Figure 2 Immunofluorescence micrographs of the endometrium from non-treated $(A-C)$ and oestrogen treated $(D-F)$ postmenopausal women after staining with an MoAb specific for collagen type $I V(A, C)$ and polyclonal antibodies against laminin $(B, D) . G$, endometrial gland. (Original magnification, $\times 250$ ).

Table 1 Immunostaining with antibodies for collagen and laminin in endometrial tissue from postmenopausal women with and without three weeks of oestrogen treatment

\begin{tabular}{|c|c|c|c|c|c|}
\hline & \multicolumn{4}{|c|}{ Collagen } & \multirow[b]{2}{*}{ Laminin } \\
\hline & Type I & Type III & Type IV & Type VI & \\
\hline Non-treated $(n=10)$ & ++ & $+/-$ & - & - & + \\
\hline Treated $(n=10)$ & +++ & +++ & ++ & ++ & ++ \\
\hline
\end{tabular}

- , no staining; + , weak staining; ++ , intense staining; +++ , very intense staining.

\section{Results}

IMMUNOHISTOCHEMICAL ANALYSIS OF THE

ENDOMETRIUM

Control sections were stained with goat antibodies against mouse immunoglobulin $G$ without prior application of the appropriate primary antibody (data not shown). When the antibodies were first allowed to react with an excess of the corresponding specific type of collagen or laminin, no immunostaining was observed.

\section{Interstitial collagens}

In the endometrium of non-treated women, strong immunostaining with the MoAb against type I collagen was evident in a fibrillar pattern (fig 1A). However, very weak or no immunostaining with the MoAb against type III collagen was observed (fig 1B). No immunostaining with the MoAb against type VI collagen was apparent in the stroma of the endometrium (fig 1C). Enhanced immunostaining with the MoAb against type I (fig 1D), type III (fig 1E), and type VI (fig 1F) collagens was observed in the stroma of the endometrium from oestrogen treated postmenopausal women, with a fibrillar pattern. In contrast, no immunostaining specific for type I, III, and VI collagens was detected in endometrial glands (figs 1D-F).

\section{Components of the basement membrane}

In the endometrium of non-treated women, no immunostaining with the MoAb against type IV collagen was observed on the basement membrane of endometrial glands (fig 2A). However, immunostaining with the polyclonal antibody against laminin was observed on the basement membrane of the endometrial glands (fig 2B). In contrast, strong immunofluorescence specific for type IV collagen and laminin was detected on the basement membrane of endometrial glands (figs 2C and D) in the endometrium of oestrogen treated women. The intensity of immunostaining of the endometrial tissues from non-treated and oestrogen treated postmenopausal women by each of the antibodies against components of the ECM was subjectively graded from $1+$ to $3+$ and the results are summarised in table 1.

INTERRUPTED SDS-PAGE OF PEPSIN SOLUBILISED COLLAGENS FROM THE ENDOMETRIUM

Interrupted SDS-PAGE revealed that the relative level of $\alpha 1$ (III) chains was higher and that of $\alpha 1$ (I) chain was lower in the endometrium of postmenopausal women treated with oestrogen than they were in the endometrium of non-treated postmenopausal women (fig 3). The ratio of the intensity of the band of $\alpha 1$ (III) to that of $\alpha 1$ (I) was (mean (SEM)) 0.07 (0.01) and $0.34(0.10)$ for the endometrium of non-treated women and the endometrium of oestrogen treated women, respectively. The ratio of the intensity of the band of $\alpha 1$ (III) to that of $\alpha 1$ (I) from the endometrium of oestrogen treated women was significantly higher than that from the endometrium of non-treated women $(p<0.01)$ (fig 4$)$.

\section{Discussion}

We investigated changes in the distribution of components and the composition of the ECM, including collagen types I, III, IV, and VI, and laminin, in the human postmenopausal endometrium with and without three weeks of oestrogen treatment. We were able to solubilise $70-85 \%$ of the collagen in the human endometrial tissues, as determined by reference to levels of hydroxyproline (data not shown). Therefore, we postulated that the extracted collagen might accurately reflect the entire complement of collagen in the tissues.

In the postmenopausal endometrium of women without oestrogen treatment, our immunohistochemical observations confirmed that type I collagen was the predominant interstitial collagen and that laminin was present on the basement membrane of endometrial glands. The endometrium of postmenopausal women treated with conjugated equine oestro- 


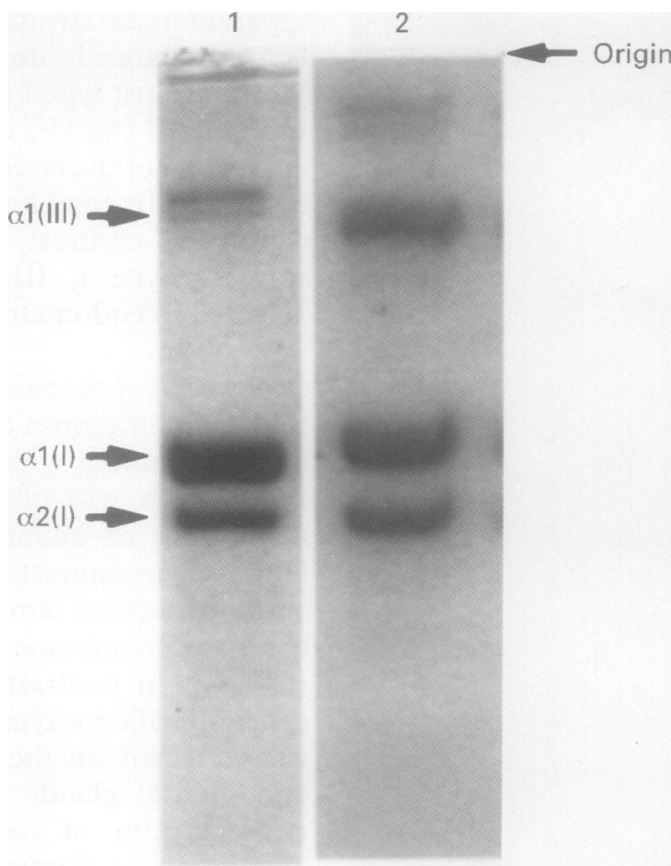

Figure 3 SDS-PAGE of pepsin solubilised collagens from the endometrium of a non-treated woman (lane 1) and an oestrogen treated woman (lane 2). Samples of heat denatured collagen ( $5 \mathrm{mg}$, lanes 1 and 2) were subjected to electrophoresis on a slab gel for one hour.

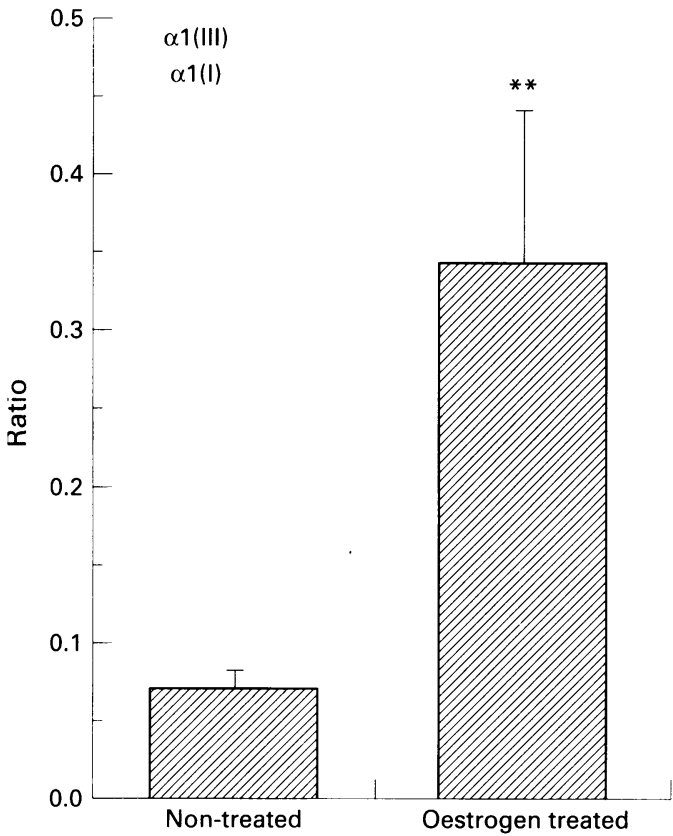

Figure 4 Relative abundance of the a1(III) chain of collagen compared with the 1 (I) chain in the endometrium of women with $(n=10)$ and without oestrogen treatment $(n=10)$. Data are presented as the means (SEM). Values were analysed for statistical significance between the two groups by ANOVA and Student's $t$ test. ${ }^{\star \star} p<0.01$.

gen was similar to the endometrium of cycling women in the proliferative phase. Enhanced immunostaining of interstitial collagens, such as types I, III, and VI, was observed with a diffuse and fibrillar pattern. Although type I and type III collagens are commonly found in combination, the ratio of type III to type I collagen in the endometrium of postmenopausal oestrogen treated women was significantly higher than that in the endometrium of postmenopausal women without oestrogen treatment. Changes in the ratio of type III to type I colla- gen have been demonstrated in the human skin in the process of aging $^{7}$ and in human atherosclerosis. ${ }^{1011} \mathrm{~A}$ possible cause of the change in the relative levels of collagens might be the effects of oestrogen on the endometrial stromal cells. Another possible cause might be alterations in the density of cells in the human endometrium. Recently, cell density dependent effects have been reported in the various types of cell, such as mesangial, ${ }^{12-14}$ endothelial, ${ }^{15}$ vascular smooth muscle, ${ }^{16-18}$ fibroblasts, ${ }^{19}{ }^{20}$ and primitive mesenchymal cells. ${ }^{21}$

It has been suggested that cell density might modulate the biological behaviour of cells, with changes in signal-transduction responses to hormonal stimulation, in growth, in the synthesis and composition of the ECM, and in the synthesis of specific proteins. ${ }^{12-14}$ Therefore, it is suggested that ovarian secretion of oestrogen might cause intense proliferation of the endometrial stromal cells and that, with increases in cell density, stromal cells might synthesise type III collagen predominantly and specifically.

In the present study with an MoAb against type VI collagen, no type VI collagen was found in the endometrium of postmenopausal women without oestrogen treatment. However, this collagen was found to be localised diffusely in the endometrium with a fine fibrillar pattern after three weeks of oestrogen treatment. This microfibrillar collagen is an unusual and unique collagen, which might anchor to the surrounding ECM. ${ }^{22}{ }^{23} \mathrm{~A}$ recent report by Mulholland $e t \mathrm{al}^{24}$ indicated that type VI collagen might play a role in trophoblastic invasion. The results of our observations suggest that oestrogen might influence the expression of type VI collagen.

Immunostaining of components of the basement membrane, such as type IV collagen and laminin, was abundant in the endometrium of postmenopausal women after oestrogen treatment. The results of our observations suggest that oestrogen might induce development of endometrial glands and, therefore, endometrial glandular cells might be involved in the increased synthesis of components of the basement membrane. The basement membrane might be involved in controlling the selective permeability to macromolecules and in structural tissue support. ${ }^{25}$ In the decidua, components of the basement membrane, such as type IV collagen and laminin, have been identified around the decidual cells. ${ }^{56}$ The pericellular accumulation of basement membrane-like components that include type IV collagen and laminin might be associated with the decidualisation of the endometrium. Therefore, it is postulated that these components of the basement membrane might play an important role in the human endometrium.

In conclusion, the present results suggest that conjugated equine oestrogen might induce alterations in the distribution of components and the composition of the ECM in the endometrium of postmenopausal women. In addition, our results provide some insights into the hormonal regulation of the characteristics of the ECM in the endometrium of postmeno- 
pausal women who are given conjugated equine oestrogen daily as hormone replacement therapy.

1 Strauss JF, Gurpide E. The endometrium: regulation and dysfunction. In: Yen SC, Jaffe RB, eds. Reproductive endocrinology: physiology, pathology, and clinical management. 3rd edn. Philadelphia: Harcourt Brace Jovanovich, 1991:309-56.

$2 \mathrm{Lin} \mathrm{CQ}$ Bissell MJ. Multi-faceted regulation of cell differentiation by extracellular matrix. FASEB $\mathcal{f}$ 1993;7:

3 Madri JA, Basson MD. Extracellular matrix-cell interactions: dynamic modulators of cell, tissue and organ ism structure and function. Lab Invest 1992;66:519-21.

4 Haralson MA. Extracellular matrix and growth factors: an integrated interplay controlling tissue repair and progression to disease. Lab Invest 1993;69:369-72.

5 Aplin JD, Charlton AK, Ayad S. An immunohistochemical study of human endometrial extracellular matrix during the menstrual cycle and the first trimester of pregnancy. Cell Tissue Res 1988;253:231-40.

6 Ooshima A, Muragaki Y. Collagen metabolism in atheroOoshima A, Muragaki Y. Collagen metabolis

7 Sykes B, Puddle B, Francis M, Smith R. The estimation of Sykes B, Puddle B, Francis M, Smith R. The estimation of
two collagens from human dermis by interrupted gel electrophoresis. Biochem Biophys Res Commun 1976;72:147280.

8 Kivirikko KI, Prockop DJ. Hydroxylation of proline in synthetic polypeptides with purified protocollagen hydroxylase. F Biol Chem 1967;242:4009-12.

9 Laemmli UK. Cleavage of structural proteins during the assembly of the head of bacteriophage T4. Nature 1970;227:680-5.

10 McCullagh KA, Balian G. Collagen characterisation and cell tranformation in human atherosclerosis. Nature 1975 ; 258:73-5.

11 Ooshima A. Collagen a B chain: increased proportion in human atherosclerosis. Science 1981;213:666-8.

12 Lermioglu F, Goyal J, Hassid A. Cell density modulates the decrease of cytosolic free $\mathrm{Ca}^{2+}$ induced by arteria natriuretic hormone, $\mathrm{S}$-nitroso- $\mathrm{N}$-acetylpenicilliamine and 8-bromo cyclic GMP in cultured rat mesangial cells. Biochem 7 1991;274:323-8.

13 Ishimura E, Sterzel RB, Budde $K$, Kashgarian $M$ Formation of extracellular matrix by cultured rat mesangia cells. Am f Pathol 1989;134:843-5.
14 Worthuis A, Boes A, Grond J. Cell density modulates growth, extracellular matrix, and protein synthesis of cultured rat mesangial cells. Am ₹ Pathol 1993;143:120919.

15 Patton WF, Yoon MU, Alexander JS, et al. Expression of simple epithelial cytokeratins in bovine pulmonary microvascular endothelial cells. F Cell Physiol 1990;143:140-9.

16 Majors AK, Ehrhart L. Cell density and proliferation modulate collagen synthesis and procollagen mRNA levels in arterial smooth muscle cells. Exp Cell Res 1992;200:16874.

17 Campbell JH, Kocher O, Skalli O, Gabbiani G, Campbell GR. Cytodifferentiation and expression of $\alpha$-smooth muscle actin mRNA and protein during primary culture of aortic smooth muscle cells. Correlation with cell density and proliferative state. Arteriosclerosis 1989;9:633-43.

18 Goodman LV, Majack RA. Vascular smooth muscle cells express distinct transforming growth factor- $\beta$ receptor phenotypes as a function of cell density in culture. $\mathcal{F}$ Bio Chem 1989;264:5244-51.

19 Rösner H, Greis C, Rodemann HP. Density-dependent expression of ganglioside GM3 by human skin fibroblasts in an all-or-none fashion, as a possible modulation of cell growth in vitro. Exp Cell Res 1990;190:161-9.

20 Halme T, Vihersaari R, Penttinen R. Lysyl oxidase activity and synthesis of desmosines in cultured human aortic cells and skin fibroblasts: comparison of cell lines from control subjects and patients with Marfan syndrome or other subjects and patients with Marfan syndrome or other
annuloaortic ectasa. Scand f Clin Lab Invest 1986;46:31-7.

21 Tsonis PA, Goetinck PK. Cell density effects of a tumor Tsonis PA, Goetinck PK. Cell density effects of a tumor
promotor on proliferation and chondrogenesis of limb bud mesenchymal cells. Exp Cell Res 1990;190:247-53.

22 Bruns R, Press W, Engvall E, Timpl R, Gross J. Type VI collagen in extracellular, 100-nm periodic filaments and fibrils: identification by immunoelectron microscopy. $f \mathrm{Cell}$ Biol 1986;103:394-404.

23 Keene DR, Engvall E, Granville RW. Ultrastructure of type VI collagen in human skin and cartilage suggests an anchoring function for this filamentous network. F Cell Biol 1988;107:1995-2006.

24 Mulholland J, Aplin JD, Ayad S, Hong L, Glasser SR. Loss of collagen type VI from rat endometrial stroma during decidualization. Biol Reprod 1992;46:1136-43.

25 Martinez-Hernandez A, Amenta PS. The basement membrane in pathology. Lab Invest 1983;48:656-77.

26 Ulla MK, Mette F, Lance AL, Reidar A. Immunochemica and ultrastructural assessment of the nature of the pericellular basement membrane of human decidual cells. Lab Invest 1985;53:624-33. 